\title{
ИЛЛЮСТРАЦИЯ К ЭПОСУ ОБ АЛПАМЫСЕ И НЕКОТОРЫЕ ПАРАЛЛЕЛИ СЮЖЕТУ В ИСКУССТВЕ ДРЕВНИХ КОЧЕВНИКОВ: К ИЗУЧЕНИЮ СЕМАНТИКИ ВИХРЕВЫХ КОМПОЗИЦИЙ
}

\author{
(C) 2018 г. Г.С. Джумабекова, Г.А. Базарбаева
}

Памятники ранних кочевников Казахстана обладают значительной информативной емкостью, особенно важное значение имеют произведения древнего искусства, изделия, декорированные в скифском зверином стиле.

Ключевые слова: археология, саки, скифы, воины, охота, конское снаряжение, вихревые композиции

\footnotetext{
Степь для казахов имела свою центральную точку там, где стояла юрта или аул, но постоянные перекочевки передвигали ее в пространстве. ...Пространство, подобно сфере, радиусами расходилось от кочевника в разные стороны, открывая беспредельные горизонты вокруг, но и возвращаясь к нему как к центру вращения. (по: Каракузова Ж.К., Хасанов М.Ш.)
}

В книге «Алпамыс батыр» из серии «Дорогое наследие», вышедшей в 1981 г. в издательстве «Жалын», есть иллюстрация, созданная известным казахстанским художником Евгением Сидоркиным [Алпамыс батыр, 1981, с. 61.] (рис. 1). На ней показана сцена поединка двух воинов-всадников. Накал борьбы присутствует во всем - в напряженных мускулах спины, плеч, в переплетенных руках, скованных в схватке сильных пальцах; передано эмоциональное состояние скакунов, показанных с раздувающимися ноздрями, в разбросанных предметах вооружения. Но более всего состояние схватки отражает круговое движение, прослеживаемое по позам лошадей.
Художник смог мастерски передать главный принцип происходящего.

В культуре сакского времени круговые композиции присутствуют в материалах разных памятников. Новые находки, в том числе полученные из элитарных погребений Сарыарки, ставят новые вопросы о семантике и функциональном назначении декоративных элементов и художественно оформленных комплексов вооружения и конского снаряжения. К таковым относятся, например, железные бляшки узды из раннесакского тасмолинского кургана 3 мог. Тасмола-5: 11 круглых железных бляшек, щиток которых плакирован золотым листом с декором в виде различных сочетаний 


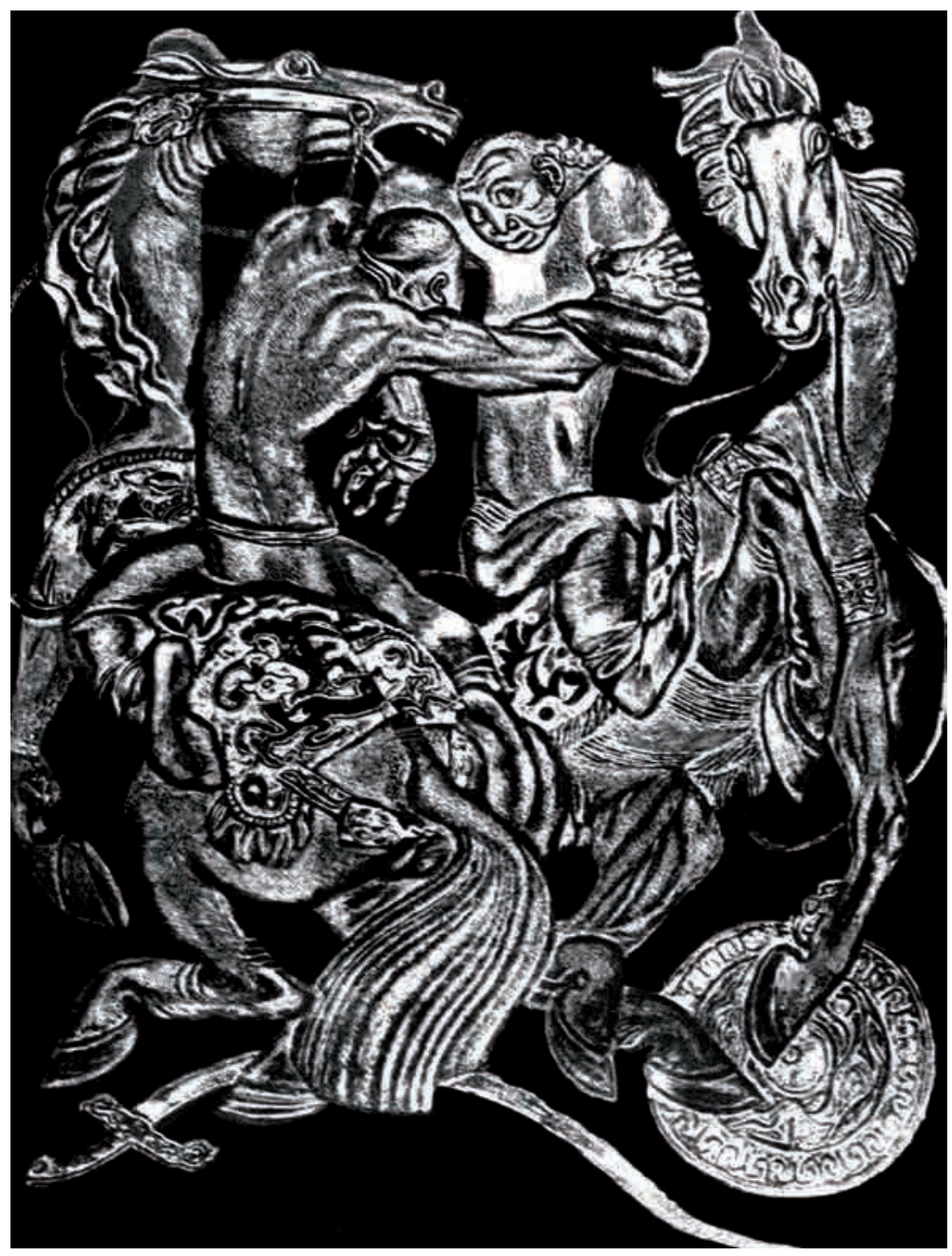

Рис. 1. Поединок (по: [Алпамыс батыр, 1981, с. 61]). Художник Е. Сидоркин

Fig. 1. The single combat (by: [Alpamys batyr, 1981]). The artist E. Sidorkin

спиралеобразно-вихревого орнамента [Кадырбаев, 1966, с. 427, рис. 71; 72] (рис. 2, 1-4). Недавние находки в Сарыарке также содержат предметы, декорированные орнаментальным мотивом в виде вихревой розетки. Жертвенник № 4 из мог. Бакыбулак (Карагандинская обл., VIII-VII вв. до н.э.) содержал комплекс конского снаряжения, выполненный из бронзы и покрытый фольгой [Бейсенов, 2011; 2017 , рис. 3; фото 1, 2] (рис. 2, 5, 6, 9). К ним можно добавить комплекс случайных находок, обнаруженный в 30 км от c. Баршатас (ВКО, Восточная Сарыарка, конец VII-VI вв. до н.э.). Предполагается, что это приклад раннесакского времени, в составе которого находились бронзовые псалии, удила, пронизи, всего 13 предметов. Семь из них - распределители уздечных ремней и застежка декорированы вихревой композицией [Бесетаев, 2015, рис. 2, 3, 4, 5; Бейсенов и др., 2017, с. 43-44] (рис. 2, 7, 8, 10). 

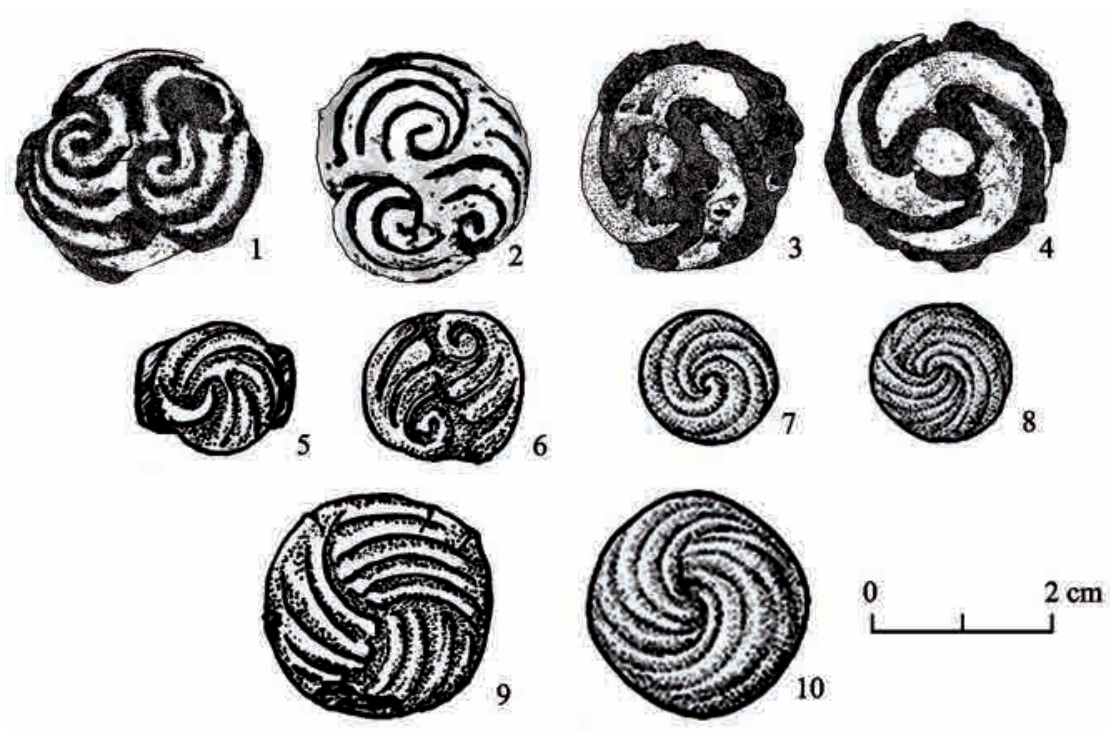

Рис. 2. Мотив вихревой розетки в материалах из Сарыарки. 1-4-Тасмола-5, к. 3 (по: [Кадырбаев, 1966]); 5, 6, 9 - Бакыбулак, жертвенник № 4 (по: Бейсенов, 2017]); 7, 8, 10 - Баршатас (по: [Бесетаев, 2015]).

Исполнители: 1-4-А. Колесникова; 5-10-Д. Дюанабаев

Fig. 2. The motif of the vortex from Saryarka. 1-4-Tasmola-5 (by: [Kadyrbayev, 1966]); 5, 6, 9-Bakybulak (by: [Beisenov, 2017]); 7, 8, 10-Barshatas

(by: [Besetayev, 2015]). The artists is: 1-4-A. Kolesnikova; 5-10-J. Janabayev

Общепринятым является тезис о том, что в культуре населения раннего железного века орнаментальные композиции не являлись только декором, нанесенным с эстетической целью, но представляли собой своеобразные знаки-символы.Так, в отношении конского убранства лаконично и емко выразилась Е.Ф. Королькова - роль всадника в идеологии общества ранних кочевников обусловило то, что декор конского снаряжения, конское убранство совмещало утилитарную, декоративную и апотропеическую функции [2012, с. 345].

Предметы конской упряжи с вихревым орнаментом происходят как из погребений, так и из жертвеннопоминальных сооружений. Среди особенностей памятников раннесакской майемерской культуры отмечено совмещение различных способов обозначения лошади в погребальном комплексе: лошади не взнуздывались, сбруя помещалась у головы лошади, в конских подхоронениях, в виде приклада в каменном ящике, на краю каменного ящика (возможно, это некоторым образом перекликается с кладами конской узды в жертвенниках). П.И. Шульга отмечает, что уздечку и седло укладывали рядом с лошадью - у морды, иногда на лежащем рядом баране, плеть лежала на сбруе или рядом. Как вариант - зафиксировано подхоронение взнузданной и оседланной лошади (VII - нач. VI в. до н.э.) [Шульга, 2016, с. 87]. Жерт- 
венники тасмолинской культуры, которые иногда содержат предметы конской узды, по мнению А.З. Бейсенова, можно воспринимать «как свидетельства проведенного обряда жертвоприношения лошади» [2017, c. 88].

Приклады с предметами конского снаряжения (мог. Измайловка, ограда 17, курган 5, ВКО, конец IX - первая половина VIII в. до н.э.; Аржан-2, Тува, вторая половина VII в. до н.э.; Биже, Жетысу, вторая половина VIII-VII в. до н.э. и др.) широко распространены в раннесакское время по всей территории культурной общности ранних кочевников [Акишев К.А., Акишев А.К., 1978; Бейсенов, Смаилов, 1998; Ермолаева, 2012, с. 74; рис. $58,1-11,13-17$; рис. 78, 1-4; Čugunov et al., 2010, Tafel 126145]. Сбруя, как и оружие, входили в престижно-знаковую систему, маркируя выделившуюся социальную группу воинов-всадников. Вероятно, все эти варианты подхоронения лошадей и комплексов конской упряжи можно считать вариантом воплощения одной и той же идеи, скорее свидетельством совершения определенного обряда, связанного с погребением и поминовением умершего. Они отражают особенности всаднического погребально-поминального обряда.

Судя по находкам кладов/прикладов раннесакского времени в жертвенниках, эти комплексы и сами выкладки из камней - жертвенники, поминальники, связываются с циклом поминальных обрядов [Бейсенов и др., 2017, с. 44]. Так, каменные выкладки, расположенные с западной стороны курганов, связывают с обрядами прощания с душой умершего, установления связи с потусторонним миром [Тишкин, Шепелева, 2006, с. 68]. А.3. Бейсенов в ареале тасмолинской культуры выявил связь жертвенников с курганами, они имеют округлую или овальную форму, диаметр от 1,5 м до 3-4 м, иногда включают предметы конской узды. Как указывалось выше, А.3. Бейсенов считает их свидетельством проведенного обряда жертвоприношения лошади. Так, комплекс Бакыбулак содержит несколько жертвенников (6) [Бейсенов, 2017, с. 88]. Различные элементы погребально-поминальных комплексов Тасмолы - околокурганные жертвенники, изваяния, менгиры, вероятно, можно связать с предшествующей бегазы-дандыбаевской культурой Центрального Казахстана.

Материалы раннесакских памятников (Приаралье - Жетысу Сарыарка - Алтай - Тува) демонстрируют удивительное сходство произведений древнего искусства, элементов погребальной обрядности из элитных погребений. В числе факторов, обусловивших общность культур, называют близость в целом мифо-ритуального комплекса. Так, в комплексе кургана Аржан-2 о роли лошади в жизни древнего кочевника, о сложности погребальнопоминального обряда с участием лошади свидетельствуют могила № 16 с 14 захороненными конями [Čugunov et al., 2010, Tafel 126-145]. Каждое животное сопровождал определенный стандартный комплекс снаряжения. Кроме того, под курганом были выявлены клады (4) с предметами конского снаряжения. Внекурганные 
сооружения, сопровождающие погребения раннескифского времени, связывает с жертвоприношением Д.Г. Савинов [2012].

Таким образом, судя по тому, что жертвенники, приклады и т.п. выявлены как элементы погребальных комплексов, можно предположить, что жертвоприношения, сооружения с прикладами являются частью сложного и продолжительного погребальнопоминального цикла. Приклады/клады, возможно, являлись заменой животного (коня). Очевидно, появление подобных комплексов обусловлено усилением значения верхового коня в жизни кочевника, воина, охотника.

Декор конского снаряжения, в том числе в виде вихревой розетки, связан с имевшими огромное значение в жизни скифов/саков войной и охотой [Бейсенов и др., 2017]. В первую очередь, предполагается, что декорирование предметов вооружения, конского снаряжения производилось с целью придать воину, коню какието особые необходимые качества, помочь в битве, помочь в преодолении пути. Позже, в период «расцвета» сакской культуры, явное выражение получило декорирование конского снаряжения сценами терзания, нападения хищников на травоядных. Этот сюжет символизировал смерть (жертвы). В целом, посредством сцен нападения/терзания хищниками травоядных передавалась идея возрождения через смерть, цикличности жизни и смерти [Полидович, 2006, с. 360, 370, 371, 373]. Размещение их на предметах вооружения и конском снаряжении воина и охотника актуально. Учитывая «героическую эпоху» ски- фов/саков, можно предположить, что представление об уподоблении битвы жертвоприношению, существование архаической концепции «битвыжертвоприношения» [Васильков, 2012 , с. 77, 81] бытовало и у кочевников. Тогда и подхоронение коней, конской упряжи и декорирование упряжи погибшего воина, охотника связано с идеей жертвоприношения.

В курганах Пазырыка, например, в сложном убранстве коней были «развернуты ансамбли зооморфных изображений, связанных с актуализацией сюжета терзания жертвенного коня» [Черемисин, 2007, с. 99]. Раскрывая ритуальную практику превращения коня в рогатое животное, Ф. Мец отмечает, мифологические представления, связанные с существованием рогатых лошадей, были распространены чрезвычайно широко. Существенным является то, что автор отмечает героическую составляющую некоторых мифов с участием рогатого коня [Мец, 2013, с. 101].

Очевидно, конь связан с Солнцем. Всеми признается, что конь был «универсальным животным в религиозно-мифологических представлениях и ритуальной практике скифо-сакских народов» [Полидович, 2006, с. 369]. Можно предположить, что спиралевидный завиток в декоре узды раннесакского времени отражает эту «солнечную» природу образа коня.

Другая линия символики декора коня как помощника в охоте и на войне проявляется в сообщениях о тактике ведения боя древних кочевников. Облавная охота, охота вообще, имела большое значение в жизни ко- 
чевника, в том числе как своеобразная школа, «тренировка», боевая подготовка воинов. Существовал такой прием облавной охоты, как замыкание в круг конниками местности с животными. После замыкания круга соблюдалась строгая очередность выстрелов, начиная с хана. У кочевников Центральной Азии такая охота имела ритуальный характер [Кушкумбаев, 2001, с. 35-36].

В литературе неоднократно приводились ссылки на описание тактики ведения боя Геродотом и Платоном, из коих следовало, что скифы предпочитали сражаться с врагом, обращаясь в бегство, о преобладании в войске скифов легковооруженной конницы, лучников. Об этом можно судить по описанию сражения войск под предводительством Александра Македонского на берегах Танаиса с кочевыми племенами: Когда все оказались на берегу, он (Македонский) пустил на скифов сначала одну гиппархию чужеземцев и четыре илы солдат, вооруженных сариссами. «Скифы встретили их, окружили на своих лошадях, поразили и скрылись беспрепятственно» [Арриан. IV. 4. 6]. Предполагается использование скифами лавы в качестве основного боевого порядка легковооружённых всадников. Высказано предположение о том, что у скифов костяк конного войска к VI в. до н.э. составляла тяжеловооружённая панцирная конница как ударная сила. Стоит заметить, что, возможно, в восточной части Степи тяжеловооруженные всадники также появились не позднее VI в. до н.э., и в более позднее время известны изображения воинов в панцирных доспехах [Горелик, 1987; Бейсенов, Джумабекова, 2014]. Предполагается, что эффективным было использование воинов в панцирных доспехах в сомкнутом строю, во главе лавы легковооружённых всадников. В битве при Фате 310/309 г. до н.э. основную роль сыграли «отборные воины», находившиеся в центре боевого строя - тяжеловооружённые всадники, их поддерживала легкая конница [Черненко, 1971, с. 37-38]. О наличии в составе скифского войска отборной конницы, когда царь находится в центре еe, пишет Диодор. Первый ряд сомкнутого строя составляла тяжеловооруженная конница, 2/3 образовывала пехота [Ворошилов, 2010, с. 19, 22]. Скифы и сарматы предстают конниками, использующими тактику прямой таранной атаки [Перевалов, 2010 , с. 229,240$]$.

Об использовании также рукопашной схватки в тактике боевых действий сарматами, вооруженными клинками, свидетельствуют письменные источники и археологические данные [Симоненко, 2009, с. 253-254]. Судя по количественному преобладанию в археологических комплексах наконечников стрел и кинжалов среди предметов вооружения, можно предположить подобную ситуацию у саков. Установлено, что прием окружения неприятельского войска использовался хунну - цель состояла в том, чтобы вывести противника в открытое место и охватить фаланги, окружив неприятеля. Боевое построение в виде круга у татар в XVI в. называлось символично «пляска» [Кушкумбаев, 2001, с. 39]. В целом тактический прием кочевников 
XIII-XVI вв. - «хоровод» конных лучников мог применяться, как предполагается, в качестве самостоятельного приема и в составе комбинированных тактических приемов [Бобров, 2016, c. 73]. А.К. Кушкумбаев проследил формирование на базе облавных охот особого военно-охотничьего института внутри кочевого общества [Кушкумбаев, 2001, с. 43].

В элементе декора - спиралевидном завитке, вихревой розетке также можно увидеть скрытое изображение борьбы, поединка (каз. жекпе-жек). В военной организации номадов особую роль играл институт военных вождей, батыров. Исход битвы определялся поединком батыров. В литературе упоминается прием «волчок» - в схватке батыры стремились в быстром круговом движении выбить копье из рук противника [Досжанов, 1983, с. 15].

Ч.Ч. Валиханов приводит свои наблюдения о круговой жертве - айналмак, которая три раза обходит вокруг тяжелобольного. «Айналайн» «обойду вокруг» - так называют, выражая любовь, например, к ребенку [Валиханов, 1984, с. 211]. Вихревая розетка, спираль, возможно, являлись не только солярной символикой, с течением времени приобретали иное наполнение.

С кругом связана тактика охоты волков: во время облавы стая окружает жертву, волки передвигаются вслед, последовательно нападая на жертву. Атакующие волки строго соблюдают дистанцию друг от друга и от будущей жертвы. Основу нападения составляют самые опытные волки, во внутреннем круге нахо- дятся лидеры стаи, их окружают менее опытные охотники [Шалыгин, Интернет-ресурс]. Здесь уместно вспомнить принятое в воинской культуре отождествление кочевников с волками (медведями), которые «терзали» слабых («гнали овец»). Любопытный, в каком-то отношении, аналогичный пример поведения прослеживается и у травоядных животных. Получила известность запись с дрона, на которой стадо северных оленей в загонах ходит по кругу. Объяснение этому приводится от лица зоологов: таким образом животное защищается от хищников. В круг выстраиваются не только олени, но и любые другие копытные дикие животные. В центре круга находятся дети и самки [Борискин, 2018].

Таким образом, в мотиве вихревой композиции - декоре конского снаряжения - можно предположить две составляющие: солярную символику коня, его ролью в обрядах жертвоприношения, и отражение тактических приемов конных воинов.

Некоторыеэлементыохотничьевоинской культуры, обусловленные системой мировоззрения, духовными ценностями общества, проявляются в искусстве, в военной тактике, демонстрируя преемственность на протяжении тысячелетий. А.X. Маргулан отмечал, что в орнаментальные композиции изделий народного искусства включались и отдельные сюжеты - охоты, единоборства богатыря с хищником и т.д. [1986, с. 87]. Особенно ярко, видимо, это проявляется в таких мотивах казахского орнамента, как шимай - спираль; бітпес - бесконечность. Они, как и мотивы 
Джумабекова. Г.С., Базарбаева Г.А. Иллюстрация к эпосу об Алпамысе и некоторые...

балдак, спирали, вихревые розетки и др. символизировали движение, неумолимый ход времени, постоянную готовность к перекочевкам [Шевцова, 2007, с. 25], возможно, приобретали военную «окраску», философское наполнение - вечный круговорот жизни и смерти, схватку на поле боя и борьбу за жизнь.

\section{ЛИТЕРАТУРА}

1. Акишев К.А., Акишев А.К. Проблема хронологии раннего этапа сакской культуры // Археологические памятники Казахстана. Алма-Ата: «Наука», 1978. C. 38-63.

2. Алпамыс батыр. Казахский героический эпос в прозаическом пересказе Сейдимбекова А. Перевод с каз. Санбаева С. Художник Сидоркин Е. Алма-Ата: «Жалын», 1981. 112 с.

3. Арриан Квинт Эппий Флавий. Индика. Бонгард-Левин Г.М., Бухарин М.Д., Вигасин А.А. Индия и античный мир. М.: «Восточная литература», 2002.

4. Бейсенов A.3. Талды-2 и памятники раннесакского времени степной Евразии // Сакская культура Сарыарки в контексте изучения этносоциокультурных процессов степной Евразии: тез. докл. Круглого стола, посвящ. 20-летию Независимости Республики Казахстан. Караганды, 2011. С. 14-20.

5. Бейсенов А.3. Тасмолинская культура Сарыарки // Казахстан в сакскую эпоху: коллективная монография. Алматы: Институт археологии им. А.Х. Маргулана, 2017. C. $59-100$.

6. Бейсенов А.З., Смаилов Ж.Е. Талдысайские удила раннетасмолинского времени в Центральном Казахстане // Проблемы изучения и сохранения исторического наследия: матер. междунар. археологической конф. Алматы, 1998. С. 271-275.

7. Бейсенов А.З., Джумабекова Г.С. Бляшка с мифологическим сюжетом из Центрального Казахстана // Известия АлтГУ. 2014. № 4. С. 42-46.

8. Бейсенов А.З., Джумабекова Г.С., Базарбаева Г.А., Дуйсенбай Д.Б., Ахияров И.К. Вихревые композиции в искусстве саков Центрального Казахстана // Археологія і давня історія України. 2017. Вип. 2 (23). С. 40-58.

9. Бесетаев Б. Случайные находки деталей конского снаряжения и воинская поясная гарнитура раннесакского времени из Восточного Казахстана // Казахстанская археология и этнология: прошлое, настоящее и будущее: матер. междунар. научн.практ. конф. «VII Оразбаевские чтения», посвящ. 550-летию образования Казахского ханства, 20-летию Ассамблеи народа Казахстана (28-29 апреля 2015). Алматы: «Қазақ университеті», 2015. С. 252-256.

10. Бобров Л.А. Тактический прием «хоровод» конных лучников в военном искусстве кочевников Великой степи XIII-XVI вв. // Средневековые тюркско-татарские государства. 2016. № 8. С. 73-83.

11. Борискин К. Зачем олени водят хороводы // Вечерняя Москва. 6 мая 2018 г.

12. Валиханов Ч.Ч. Тенкри (бог) // Собр. соч. в 5 т. Алма-Ата: Главная ред. Казахской советской энциклопедии, 1984. Т. 1. С. 208-215.

13. Васильков Я.В. Битва как жертвоприношение (По данным древнеиндийской традиции) // Жертвоприношение в архаике: атрибуция, назначение, цель: сб. научн. тр. семинара «Теория и методология архаики». Под ред. М.Ф. Альбедиль, Д.Г. Савинова. СПб.: МАЭ РАН, 2012. Вып. V. С. 74-86. 
14. Ворошилов А.Н. Копьеносцы в войске скифского времени на Среднем Дону // Древности. Харьков, 2005. С. 19-23.

15. Горелик М.В. Сакский доспех. В: Пиотровский Б.Б. (отв. ред.) // Центральная Азия. Новые памятники письменности и искусства. М.: Наука, 1987. С. 110-133, 367-373.

16. Досжанов Д. Шелковый путь. Алма-Ата: «Жазушы», 1983. 605 с.

17. Ермолаева А.С. Памятники предгорной зоны Казахского Алтая (эпоха бронзы-раннее железо). Алматы: Институт археологии им. А.Х. Маргулана, 2012. 238 с., ил.

18. Кадырбаев М.К. Памятники тасмолинской культуры // Маргулан А.Х., Акишев К.А., Кадырбаев М.К., Оразбаев А.М. Древняя культура Центрального Казахстана. Алма-Ата: «Наука», 1966. С. 303-433.

19. Королькова Е.Ф. Чепраки с полумерлонами: конское снаряжение как элемент сакральной символики // Золото, конь и человек: сб. ст. к 60-летию А.В. Симоненко. Киев: КНТ, 2012. С. 345-352.

20. Кушкумбаев А.К. Военное дело казахов в XVII-XVIII веках. Алматы: ДайкПресс, 2001. 172 c.

21. Маргулан А.Х. Казахское народное прикладное искусство. Алма-Ата: «Онер», 1986. T. $1.256 \mathrm{c}$.

22. Мец Ф. О возможных семантических параллелях «рогатым» лошадям пазырыкской культуры // Теория и практика археологических исследований. 2013. № 1 (7). C. 91-102.

23. Перевалов С.M. Тактические трактаты Флавия Арриана: Тактическое искусство; Диспозиция против аланов. Комментарий. М.: “Памятники исторической мысли", 2010. С. 181-300.

24. Полидович Ю.Б. Хищник и его жертва: выражение круговорота жизни и смерти средствами скифского зооморфного кода // Структурно-семиотические исследования в археологии. Донецк, 2006. Т. 3. С. 355-398.

25. Савинов Д.Г. Идея множественности как залог успешного жертвоприношения // Жертвоприношение в архаике: атрибуция, назначение, цель: сб. научн. тр. семинара «Теория и методология архаики». СПб., 2012. Вып. 5. С. 49-62.

26. Симоненко А.В. Сарматские всадники Северного Причерноморья. СПб.: Факультет филологии и искусств СПбГУ, 2009. 328 с., ил.

27. Тишкин А.А., Шепелева Е.В. Изучение «поминальных» сооружений пазырыкской культуры Алтая // Теория и практика археологических исследований. 2006. Вып. 2. С. 57-75.

28. Черненко E.B. О времени и месте появления тяжёлой конницы в степях Евразии // Проблемы скифской археологии. МИА. 1971. № 177. С. 35-38.

29. Черемисин Д.В. К дискуссии о семантике искусства звериного стиля и реконструкции мировоззрения носителей пазырыкской культуры // Археология, этнография и антропология Евразии. 2007. № 3 (31). С. 87-102

30. Шалыгин А. Секреты волчьей охоты: охота волчьей стаи была смоделирована на компьютере Учеными США и Испании // National Explorer. URL: http://www. nexplorer.ru/news_12487.htm

31. Шевиова A. Казахский народный орнамент: истоки и традиция. М.: Московский фонд «Казахская диаспора», 2007. 240 с., ил.

32. Шульга П.И. Могильник раннескифского времени Гилёво-10 в предгорьях Алтая. Новосибирск: ИПЦ НГУ, 2016. 258 с.

33. Čugunov K.V., Parzinger H., Nagler A. Der skythenzeitliche Fürstenkurgan Aržan 2 in Tuva. Archäologie in Eurasien 26. Steppenvölker Eurasiens 3. Mainz: Verlag Philipp von Zabern, 2010. 
Сведения об авторах:

Джумабекова Гульнара Саиновна - ведущий научный сотрудник, Институт археологии им. А.Х. Маргулана (г. Алматы, Казахстан); gdzhuma@mail.ru

Базарбаева Галия Аппазовна - ведущий научный сотрудник, Институт археологии им. А.Х. Маргулана (г. Алматы, Казахстан); galiya2002@gmail.com

\title{
АЛПАМЫС ЖЫРЫНА ИЛЛЮСТРАЦИЯ ЖӘНЕ ЕЖЕЛГІ КӨШПЕЛІЛЕР ӨНЕРІНІН ЖЕЛІСІНІН КЕЙБІР ПАРАЛЛЕЛДЕРІ: ҚҰЙЫНДЫ КОМПОЗИЦИЯ СЕМАНТИКАСЫНЫН ЗЕРТТЕЛУІНЕ
}

\author{
Г.С. Жұмабекова, Ғ.А. Базарбаева
}

Қазақстанның ежелгі көшпелілерінің ескерткіштері айтарлықтай ақпараттқа ие, соның ішінде ерекше маңызға ежелгі өнері мен сақтардың аң стилінде безендірілген бұйымдары жатады.

Түйін сөздер: археология, сақтар, скифтер, жауынгерлер, аң аулау, атәбзелдері, құйынды композиция

\section{ILLUSTRATION TO THE EPOSE ABOUT ALPAMYS AND SOME PARALLELS TO THE FABLE IN THE ART OF ANCIENT NOMADS: TO THE STUDYING THE SEMANTICS OF VORTEX COMPOSITIONS}

\section{G.S. Jumabekova, G.A. Bazarbayeva}

The site of the early nomads of Kazakhstan have a significant informative capacity, especially important are examples of ancient art, products decorated in the Scythian animal style.

Keywords: archaeology, Sakas, Scythians, warriors, hunting, horse equipment, whirling compositions

\section{REFERENCES}

1. Akishev, K. A., Akishev, A. K. 1978. In Arheologicheskie pamyatniki Kazahstana (Archaeological monuments of Kazakhstan). Alma-Ata: "Nauka" Publ., 38-63 (in Russian).

2. Alpamys batyr. Kazakh heroic epos in prosaic retelling by Seidimbekov, A. Translated from Kazakh of Sanbayev, S. Artist Sidorkin, E. 1981. Alma-Ata: "Jalyn" Publ. (in Russian).

3. Arrian Kvint Eppiy Flaviy, 2002. Indika. Bongard-Levin, G. M., Buharin, M. D., Vigasin, A. A. Indiya $i$ antichnyiy mir (India and the ancient world). Moscow: «Vostochnaya literatura» Publ. (in Russian).

4. Beisenov, A. Z. 2011. In Beisenov, A. Z. (ed.) Sakskaya kultura Saryiarki v kontekste izucheniya etnosotsiokulturnyih protsessov stepnoy Evrazii (Sak culture of Saryarka in the context of the study of the ethnosocial and cultural processes of the steppe Eurasia). Karagandy, 14-20 (in Russian).

5. Beisenov, A. Z. 2017. In Beisenov, A. Z. (ed.) Kazahstan v sakskuyu epohu (Kazakhstan in the Saka era). Almaty: Archaeology Institute after A.Kh. Margulan, 59-100 (in Russian).

6. Beisenov, A. Z., Smailov, J. E. 1998. In Problemy izucheniya i sohraneniya istoricheskogo naslediya (Problems of studying and preserving historical heritage). Almaty, 271-275 (in Russian).

7. Beisenov, A. Z., Jumabekova, G. S. 2014. In Izvestiya AltGU (News of Altay State University), 4, 42-46 (in Russian). 
8. Beisenov, A. Z., Jumabekova, G. S., Bazarbayeva, G. A., Duisenbay, D. B., Akhiyarov, I. K. 2017. In Skory, S. A., Gorbanenko, S. A. Boltrik, Yu. V. (eds.). Arheologiya $i$ davnya istoriya Ukraini (Archeology and ancient history of Ukraine), 2 (23), 40-58 (in Russian).

9. Besetayev, B. 2015. In Kalysh, A. B. (ed.). Kazahstanskaya arheologiya i etnologiya: proshloe, nastoyaschee i buduschee (Kazakhstan archeology and ethnology: past, present and future). Almaty: «Qazaq University» Publ., 252-256 (in Russian).

10. Bobrov, L. A. 2016. In Srednevekovyie tyurksko-tatarskie gosudarstva (Medieval Turkic-Tatar states), 8, 73-83 (in Russian). Russian).

11. Boriskin, K. 2018. In Vechernyaya Moskva (Evening Moscow), 6 may 2018 (in

12. Valikhanov, Ch. Ch. 1984. In Sobr. soch. v 5 t. (Collected Works), 1. Alma-Ata: Glavnaya red. Kazahskoy sovetskoy entsiklopedii, 208-215 (in Russian).

13. Vasilkov, Ya. V. 2012. In Albedil, M. F., Savinov, D. G. (eds.) Zhertvoprinoshenie $v$ arhaike: atributsiya, naznachenie, tsel (Sacrifice in the archaic: attribution, purpose), 5. Saint Petersburg: MAE RAS, 74-86 (in Russian).

14. Voroshilov, A. N. 2005. In Drevnosti (Antiquities). Harkov, 19-23 (in Russian).

15. Gorelik, M. V. 1987. In Piotrovskii, B. B. (ed.). Tsentralnaya Aziya. Novye pamyatniki pismennosti i iskusstva (Central Asia. New sites of writing and art). Moscow: "Nauka" Publ., 110-133, 367-373 (in Russian). Russian).

16. Dosjanov D. 1983. Shelkovyi put (Silk Road). Alma-Ata: “Jazushy” Publ. (in

17. Ermolaeva, A. S. 2012. Pamyatniki predgornoy zony Kazahskogo Altaya (epoha bronzy - rannee zhelezo) (The sites of the foothill zone of the Kazakh Altay (Bronze AgeEarly Iron)). Almaty: Institute archaeology after A.Kh. Margulan (in Russian).

18. Kadyrbayev, M. K. 1966. In Margulan, A. Kh. (ed.) Drevnyaya kultura Tsentralnogo Kazahstana (Ancient culture of Central Kazakhstan). Alma-Ata: "Nauka", 303433 (in Russian).

19. Korolkova, E. F. 2012. In Simonenko A.V. (ed.). Zoloto, kon i chelovek (Gold, horse and man). Kyiv: KNT, 345-352 (in Russian)

20. Kushkumbayev, A. K. 2001. Voennoe delo kazahov v XVII-XVIII vekah (Military affairs of the Kazakhs in the XVII-XVIII centuries). Almaty: Daik-Press (in Russian).

21. Margulan, A. Kh. 1986. Kazahskoe narodnoe prikladnoe iskusstvo (Kazakh national applied art), 1. Alma-Ata: «Oner» (in Russian).

22. Mets, F. 2013. In Tishkin, A. A. (ed.). Teoriya i praktika arheologicheskih issledovanii (Theory and practice of archaeological research), 1 (7), 91-102 (in Russian).

23. Perevalov, S. M. 2010. Takticheskie traktaty Flaviya Arriana: Takticheskoe iskusstvo; Dispozitsiya protiv alanov. Kommentarii (Tactical treatises by Flavius Arrián: Tactical art; Disposition against Alans. Comment). Moscow: Pamyatniki istoricheskoy mysli, 181-300 (in Russian).

24. Polidovich, Yu. B. 2006. In Strukturno-semioticheskie issledovaniya v arheologii (Structural and semiotic studies in archaeology), 3. Donetsk, 355-398 (in Russian).

25. Savinov, D. G. 2012. In Albedil, M. F., Savinov, D. G. (eds.). Zhertvoprinoshenie $v$ arhaike: atributsiya, naznachenie, tsel (Sacrifice in the archaic: attribution, purpose), 5. Saint Petersburg, 49-62 (in Russian).

26. Simonenko, A. V. 2009. Sarmatskie vsadniki Severnogo Prichernomorya (Sarmatian horsemen of the Northern Black Sea). Saint Petersburg: Faculty philology and art of the Saint Petersburg State University (in Russian).

27. Tishkin, A. A., Shepeleva, E. V. 2006. In Tishkin, A. A. (ed.). Teoriya i praktika arheologicheskih issledovanii (Theory and practice of archaeological research), 2, 57-75 (in Russian). 
28. Chernenko, E. V. 1971. In Liberov, P. D., Gulyaev, V. I. (eds.). Problemy skifskoi arheologii (Problems of Scythian archeology). MIA, 177, 35-38 (in Russian).

29. Cheremisin, D. V. 2007. In Arheologiya, etnografiya $i$ antropologiya Evrazii (Archeology, Ethnography and Anthropology of Eurasia), 3 (31), 87-102 (in Russian).

30. Shalygin, A. In National Explorer. URL: http://www.nexplorer.ru/ news_12487.htm (in Russian).

31. Shevtsova, A. 2007. Kazahskii narodnyi ornament: istoki i traditsiya (Kazakh folk ornament: origins and tradition). Moscow: Moscow found «Kazahskaya diaspora» (in Russian).

32. Shulga, P. I. 2016. Mogilnik ranneskifskogo vremeni Gilyovo-10 v predgoryah Altaya (Early Scythian burial ground Gilyovo-10 in Altay). Novosibirsk: Novosibirsk State University Publ. (in Russian).

33. Čugunov, K. V., Parzinger, H., Nagler, A. Der skythenzeitliche Fürstenkurgan Aržan 2 in Tuva. Archäologie in Eurasien 26. Steppenvölker Eurasiens 3. Mainz: Verlag Philipp von Zabern, 2010 (German).

\section{About the Authors:}

Jumabekova Gulnara S. Leading Researcher, A.Kh. Margulan Archeology Institute, Almaty, Kazakhstan, gdzhuma@mail.ru

Bazarbayeva Galiya A. Leading Researcher, A.Kh. Margulan Archeology Institute, Almaty, Kazakhstan, galiya2002@gmail.com

\footnotetext{
Мүдделер қақтығысы туралы ақпаратты ашу. Авторлар мүдделер қақтығысының жоқтығын мәлімдейді. / Раскрытие информации о конфликте интересов. Авторы заявляют об отсутствии конфликта интересов. / Disclosure of conflict of interest information. The authors claims no conflict of interest.

Мақала туралы ақпарат / Информация о статье / Information about the article.

Редакцияға түсті / Поступила в редакцию / Entered the editorial office: 23.10.2018.

Рецензенттер мақұлдаған / Одобрено рецензентами / Approved by reviewers: 25.10.2018.

Жариялауға қабылданды / Принята к публикации / Accepted for publication: 27.10.2018.
} 